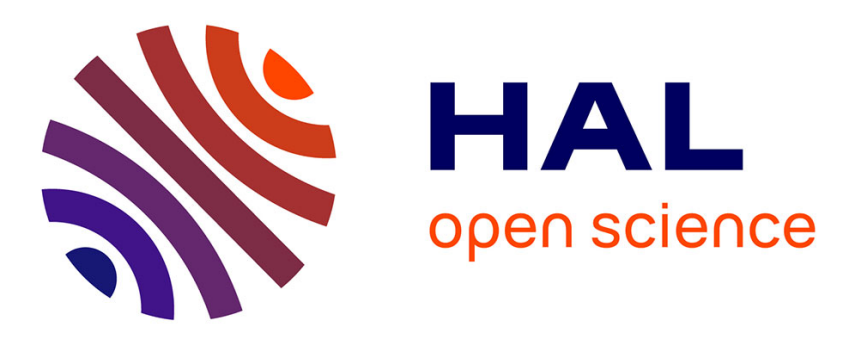

\title{
Plasma action on helium flow in cold atmospheric pressure plasma jet experiments
}

Thibault Darny, Jean-Michel Pouvesle, Jérôme Fontane, Laurent Joly, Sébastien Dozias, Éric Robert

\section{- To cite this version:}

Thibault Darny, Jean-Michel Pouvesle, Jérôme Fontane, Laurent Joly, Sébastien Dozias, et al.. Plasma action on helium flow in cold atmospheric pressure plasma jet experiments. Plasma Sources Science and Technology, 2017, vol. 26 ( $\left.{ }^{\circ} 10\right)$, pp.105001-105012. 10.1088/1361-6595/aa8877 . hal-01596263

\section{HAL Id: hal-01596263 \\ https://hal.science/hal-01596263}

Submitted on 27 Sep 2017

HAL is a multi-disciplinary open access archive for the deposit and dissemination of scientific research documents, whether they are published or not. The documents may come from teaching and research institutions in France or abroad, or from public or private research centers.
L'archive ouverte pluridisciplinaire HAL, est destinée au dépôt et à la diffusion de documents scientifiques de niveau recherche, publiés ou non, émanant des établissements d'enseignement et de recherche français ou étrangers, des laboratoires publics ou privés. 


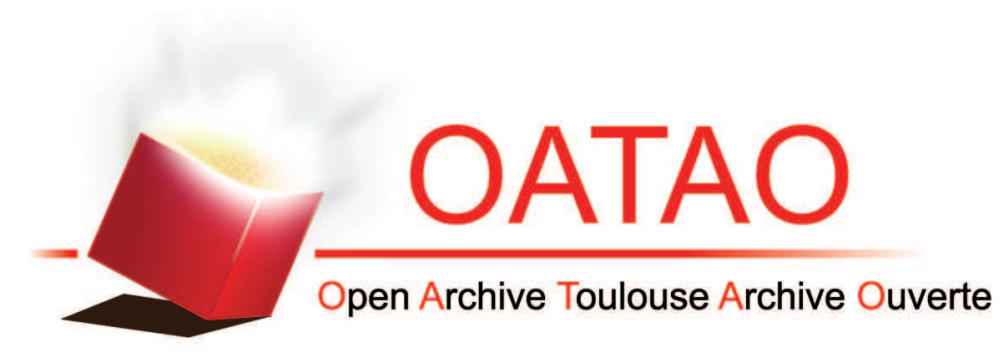

\section{Open Archive Toulouse Archive Ouverte (OATAO)}

OATAO is an open access repository that collects the work of some Toulouse researchers and makes it freely available over the web where possible.

This is an author's version published in: https://oatao.univ-toulouse.fr/18412

Official URL : https://doi.org/10.1088/1361-6595/aa8877

\section{To cite this version :}

Darny, Thibault and Pouvesle, Jean-Michel and Fontane, Jérôme and Joly, Laurent and Dozias, Sébastien and Robert, Éric Plasma action on helium flow in cold atmospheric pressure plasma jet experiments. (2017) Plasma Sources Science and Technology, vol. 26 ( $\left.n^{\circ} 10\right)$. pp. 105001-105012. ISSN 0963-0252

Any correspondence concerning this service should be sent to the repository administrator: tech-oatao@listes-diff.inp-toulouse.fr 


\title{
Plasma action on helium flow in cold atmospheric pressure plasma jet experiments
}

\author{
T Darny $^{1}$, J-M Pouvesle ${ }^{1}$, J Fontane ${ }^{2}$, L Joly ${ }^{2}$, S Dozias ${ }^{1}$ and E Robert ${ }^{1}$ \\ ${ }^{1}$ GREMI UMR 7344 CNRS/Université d'Orléans, Orléans, F-45067, France \\ ${ }^{2}$ ISAE-SUPAERO, Université de Toulouse, Toulouse, F-31400, France \\ E-mail: eric.robert@univ-orleans.fr
}

\begin{abstract}
In this work, helium flow modifications, visualized by schlieren imaging, induced by the plasma generated in a plasma jet have been studied in conditions used for biomedical treatments (jet being directed downwards with a low helium flow rate). It has been shown that the plasma action can shift up to few centimeters downstream the effects of buoyancy, which allows to the helium flow to reach a target below in conditions for which it is not the case when the plasma is off. This study reveals the critical role of large and long lifetime negative ions during repetitive operations in the $\mathrm{kHz}$ regime, inducing strong modifications in the gas propagation. The cumulative added streamwise momentum transferred to ambient air surrounding molecules resulting from a series of applied voltage pulses induces a gradual built up of a helium channel on tens of millisecond timescale. In some conditions, a remarkable stable cylindrical helium channel can be generated to the target with plasma supplied by negative polarity voltage pulses whereas a disturbed flow results from positive polarity operation. This has a direct effect on air penetration in the helium channel and then on the reactive species production over the target which is of great importance for biomedical applications. It has also been shown that with an appropriate combination of negative and positive polarity pulses, it is possible to benefit from both polarity features in order to optimize the plasma plume propagation and plasma delivery to a target.
\end{abstract}

Keywords: cold atmospheric pressure plasma jet, schlieren diagnostic, ionic wind, negative ions, electric field, plasma plume, plasma medicine

\section{Introduction}

The diversity of cold atmospheric pressure plasma jet sources has led to a large variety of applications developed over the past 10 years. Several major reviews were published on these devices [1] and their ability to produced reactive species [2]. In order to increase the efficiency of treatments with the control of reactive species production and deposition on the treated samples, one critical challenge is the study of the interaction between the plasma and the gas flow. As shown by Murakami et al [3], the air penetration inside the plasma plume highly affects the plasma chemistry. More recently, the influence of ambient air was also reported by Takeda et al [4] with a helium plasma jet on a treated copper wire. Together with the plasma-target interaction [5], the mechanism leading to the gas flow modifications induced by the plasma is an important feature which must be taken into account. One of the first study reported on the gas flow modifications was made by $\mathrm{Oh}$ et al [6]. They visualized the helium flow with schlieren imaging and they reported that the plasma enhanced the transition from laminar to turbulent regime. Two hypotheses were proposed: thermal effects associated with the gas heating and electrohydrodynamic (EHD) force due to ion momentum transfers to neutrals (ionic wind). Jiang et al [7] evidenced that the helium flow could acquire forward momentum with plasma. Gashemi et al [8] have observed for multiple helium plasma jets the earlier onset of turbulence and they emphasized on the role of thermal effects. Shao et al [9], for an argon plasma jet, have found that adding an electrostatic force in the numerical simulation allowed to get a 
forward momentum in the flow which was in agreement with their experimental observations. They also emphasized on the role of the argon mole fraction variation in the flow, resulting in plasma plume length variation, as firstly described by Karakas et al [10] in the case of a helium plasma jet. In several studies, the onset of a turbulent flow induced by the plasma $[11,12]$ was associated to a reduction of the plasma plume length, due to a higher air mixing in the working flow $[13,14]$. In Darny et al [15], for neon and helium fed Plasma Gun (PG), it was reported that various complex stable plasma plume patterns were either obtained with pulse repetition rate variation for a fixed gas flow rate, or with flow rate variation for a fixed pulse repetition rate. Furthermore, it was also shown that a given plasma plume pattern was associated to a given couple of values for both the flow rate and the pulse repetition rate. More recently, similar plume modifications with a frequency dependence was also reported by Xian et al [16]. Papadopoulos et al [17], with both schlieren visualization and numerical model, emphasized on the predominance of the EHD force on the thermal effects, in their helium plasma jet. In the study of Boselli et al [18], with a helium plasma jet, it was evidenced that a turbulent perturbation was triggered by the voltage pulse. The fast rate of the CCD camera used for schlieren imaging allowed to track the perturbation convecting downstream in the helium flow. Several hypotheses were proposed to explain the perturbation formation: gas heating, ionic wind, local pressure increase and variation of gas transport properties. In the study of Zhang et al [19], with an argon plasma jet, it was observed that the increase of the temperature near the capillary outlet was responsible for an increase of the gas flow velocity, leading to a reduction of the length of the jet potential core. Nevertheless, for a higher plasma power, the authors also observed an increase of the potential core length and the role of EHD force could not totally be excluded. In the numerical study of Hasan et al [20] and in the experimental and numerical study of Zheng et al [21], the gas heating was also found to be a major cause for the helium flow modifications. In previous publications of Robert et al [22], it was shown that the helium flow was differently affected with a distant metallic target set downstream the capillary outlet, at grounded or at floating potential, and with the use of positive or negative applied voltage polarity [23]. These observations supported the action of the EHD force to be responsible for the changes in the flow. The present paper is devoted to a more detailed study of these previously reported observations [22, 23] through a larger parametric study of the channeling features of the helium flow with the PG.

The predominance of either the EHD force with ionic wind or the thermal effects with gas heating regarding the gas flow modifications reported for many cold atmospheric pressure plasma jets remains an open question. The diversity of plasma jet configurations and power supplies may significantly influence the conclusions since they vary from one plasma jet experiment to another. In addition, it can be pointed out that the approach of gas flow modification in cold atmospheric pressure plasma jet, either the origin is thermal or EHD, has often been associated so far to the turbulence phenomena in fluids. In this paper, to the best of our knowledge, we provide the first detailed analysis on the synergistic effects between the helium flow and the plasma induced EHD streamwise momentum, achieved in a laminar flow condition. The experimental setup is presented in section 2 . The results and discussion are detailed in section 3 : plasma induced effects on the helium flow expansion, time resolved helium channeling dynamics, role of positive and negative ions with a comparison of previously reported results on plasma actuator discharge. Finally, the use of the helium channeling properties for plasma delivery on target are demonstrated. Concluding remarks are presented in section 4.

\section{Experimental setup}

The plasma jet used in this work is a PG [24]. Figure 1(a) shows a schematic view of the PG. Briefly, the PG is a coaxial dielectric barrier discharge reactor with a quartz capillary, in this work flushed with helium and powered by $\mu$ s duration voltage pulses. A $12 \mathrm{~cm}$ long dielectric quartz capillary with a $4 \mathrm{~mm}$ inner diameter and a $6 \mathrm{~mm}$ outer diameter was used. A $2 \mathrm{~cm}$ long electrode is set inside the capillary. Helium is injected through this inner hollowed electrode $(0.8 \mathrm{~mm}$ inner diameter). In this work, the helium flow rate was set at $0.51 \mathrm{~min}^{-1}$. This low flow rate condition corresponds to the flow range used during biomedical treatments with the PG [25-27]. A $5 \mathrm{~mm}$ wide grounded ring electrode is set on the outer surface of the quartz capillary overlapping downstream the tip of the inner electrode by few millimeters. The $\mu \mathrm{s}$ voltage pulse waveform is shown in figure 1(b). The maximum amplitude being reached $2 \mu$ s after the voltage pulse onset. The voltage pulse presents damped oscillations from 4 to $20 \mu \mathrm{s}$. The maximum amplitude (referred to as 'the applied voltage') can be tuned from 2 to $20 \mathrm{kV}$. The voltage pulse shape is the same for either positive or negative polarity. The pulse repetition rate can be tuned from single shot regime to $5 \mathrm{kHz}$. Several jet configurations are used: with a metallic target (grounded or at floating potential) in front of the jet located at various distances and without the target in front of the jet i.e. 'free jet'.

Time resolved plasma plume propagation downstream of the capillary outlet is visualized through ICCD imaging (PIMAX 3 ICCD camera), with respect to the voltage pulse onset. In order to avoid any misunderstanding between the plasma jet and the helium jet (i.e. the helium flow expansion in the ambient air), the latter will be referred to as the 'helium flow'.

The helium flow is visualized with a schlieren optical bench in $\mathrm{Z}$ type configuration as sketched in figure 1(d). The parabolic mirrors are $20 \mathrm{~cm}$ in diameter and have a focal distance of $1 \mathrm{~m}$. The light source is a green light diode. A fast CCD camera (IDT-Streal XS-3) with a $135 \mathrm{~mm}$ focal objective is used to visualize the helium flow expansion in the ambient air. Briefly, the schlieren technique is an optical technique used to visualize the variation of the refractive index of the medium (helium expanding in the air). A knife edge is set at the focal point of the parabolic mirror, so that all 


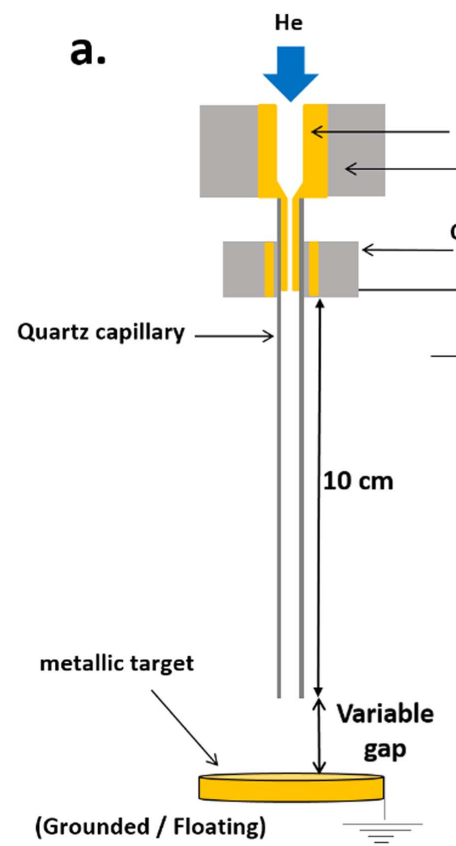

Inner high voltage electrode

Delrin ${ }^{\oplus}$ assembly

Outer grounded ring electrode

encapsulated with Delrin ${ }^{\oplus}$
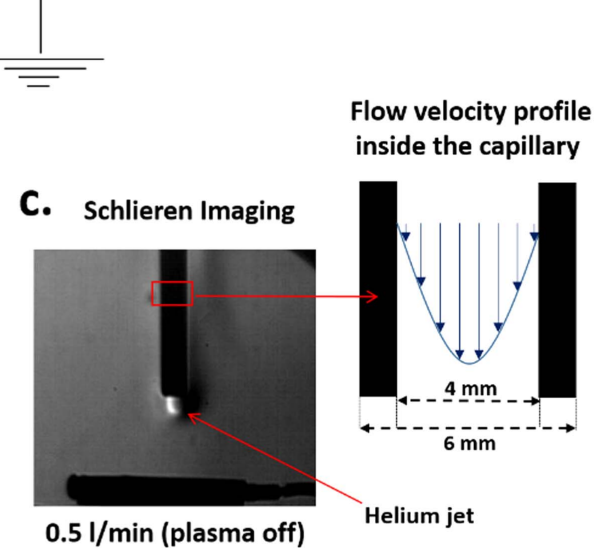

b.

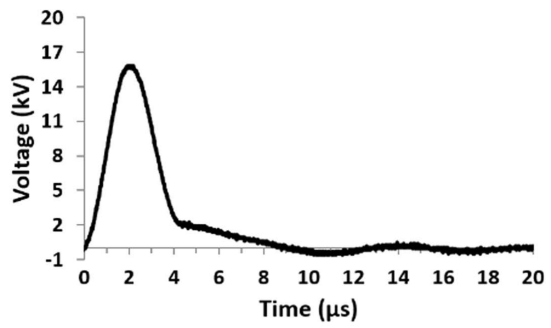

d.

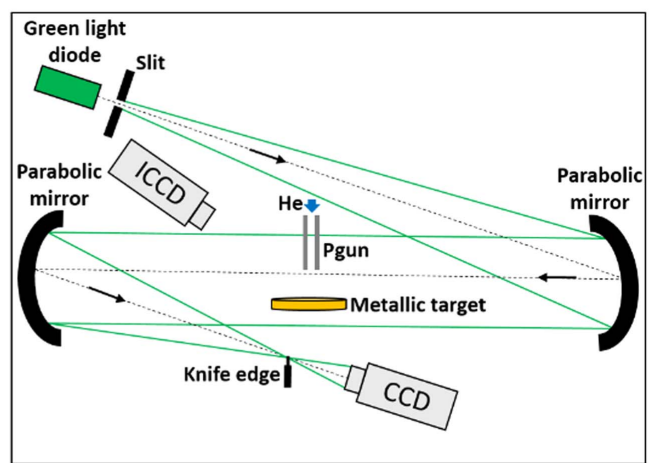

Figure 1. Schematic view of the PG (a). Typical voltage pulse waveform applied on the inner electrode (b). Schlieren imaging of the helium flow downstream of the capillary outlet and representation of the parabolic velocity profile established within the capillary (c). Optical schlieren bench in $\mathrm{Z}$ type configuration (d).

the non-refracted light beams are blocked by this knife. The refracted light beams are not focalized on the knife and formed a filtered image with a higher contrast. Details about the technique can be found in the book of G S Settles [28].

Figure 1(c) shows the helium flow expanding in the air downstream of the capillary outlet for a $0.51 \mathrm{~min}^{-1}$ flow rate, when the plasma is off. In this case, the helium flow only flows $0.4 \mathrm{~cm}$ downstream of the capillary outlet before going upward under the action of buoyancy force.

In a $4 \mathrm{~mm}$ diameter capillary for a $0.51 \mathrm{~min}^{-1}$ flow rate, the flow regime is laminar (Hagen-Poiseuille regime [29]) and transition to turbulence is not observable (Reynolds number of 22.5 at atmospheric pressure and ambient temperature). For a $0.51 \mathrm{~min}^{-1}$ flow rate in a $4 \mathrm{~mm}$ inner diameter capillary, the gas bulk velocity is $0.66 \mathrm{~m} \mathrm{~s}^{-1}$.

The gas flow modifications induced by the plasma effects have been recorded at a rate of 200 frames per second (fps) and $1000 \mathrm{fps}$. Time resolved gas flow dynamics is visualized right after the plasma is turned on.

\section{Results and discussion}

\subsection{Plasma induced effects on the helium flow expansion}

Figure 2 shows the influence of the plasma induced effects on the helium flow. The helium flow with plasma off is shown in figure 2(a). Figures 2(b) and (c) show the helium flow modification induced by the plasma activation, with a grounded metallic target located respectively $2 \mathrm{~cm}$ and $4 \mathrm{~cm}$ downstream of the capillary outlet. For both configurations, the applied voltage is $10 \mathrm{kV}$ for negative and positive polarities.
The plasma plume is imaged with ICCD, for each of these two configurations.

As described in figure 1, without plasma, the helium flow does not reach the target. It expands only $0.4 \mathrm{~cm}$ downstream of the capillary outlet because of the buoyancy. When the plasma is turned on (figure 2(b)), the flow expansion is enhanced so that the helium flow reaches the target. Both for negative and positive polarities, a helium channel is generated between the capillary outlet and the target. However, its shape is drastically dependent on the used polarity. For negative polarity, a conical helium channel is observed, with a spreading of the flow over the target surface. For positive polarity, a twisty helium channel is observed and the helium flow doesn't spread over the target surface. It can be seen that the positive plasma plume is connected to the target with a similar twisty shape and multiple branching. However, surprisingly, while the helium flow spreads over the whole target surface for negative polarity, the negative plasma plume only propagates $2 \mathrm{~mm}$ beyond the capillary outlet and does not connect to the target.

For the same $10 \mathrm{kV}$ applied voltage condition, when the grounded metallic target is located $4 \mathrm{~cm}$ downstream of the capillary outlet (figure 2(c)), the helium flow still reached the distant target below for negative polarity. For positive polarity in this configuration, the helium flow downstream expansion is drastically reduced $(1 \mathrm{~cm})$. It is even reduced compared to the $2 \mathrm{~cm}$ target gap configuration. Conversely to this previous case, it can be seen that the positive plasma plume does not connect to the target. While the shapes of the plasma plume and the one of the helium flow are still similar for positive polarity, in the case of negative polarity the helium flow 


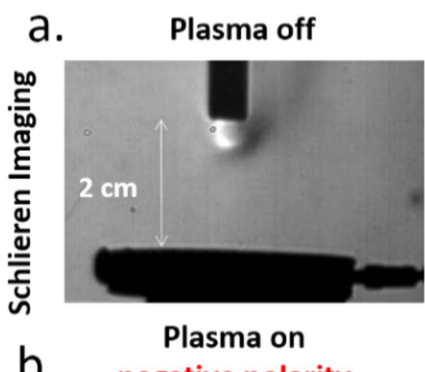

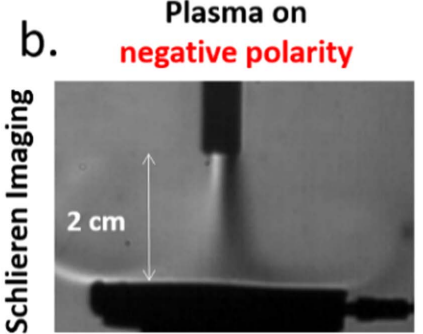

Plasma on positive polarity
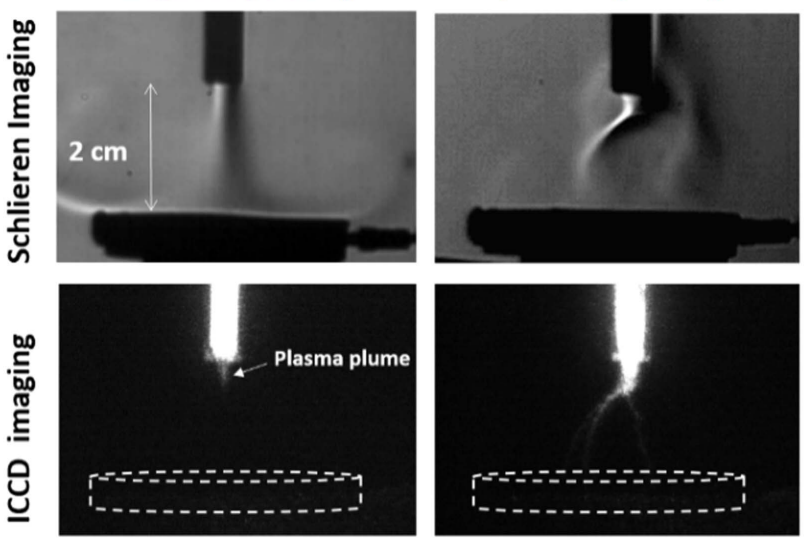

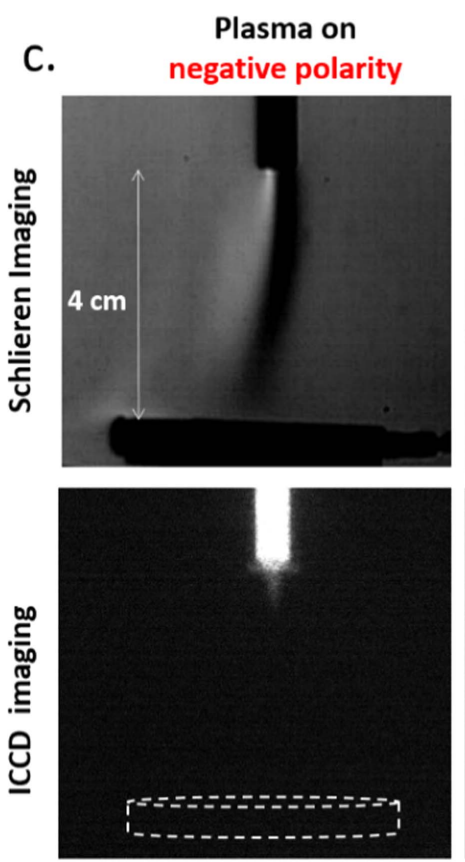

Plasma on positive polarity
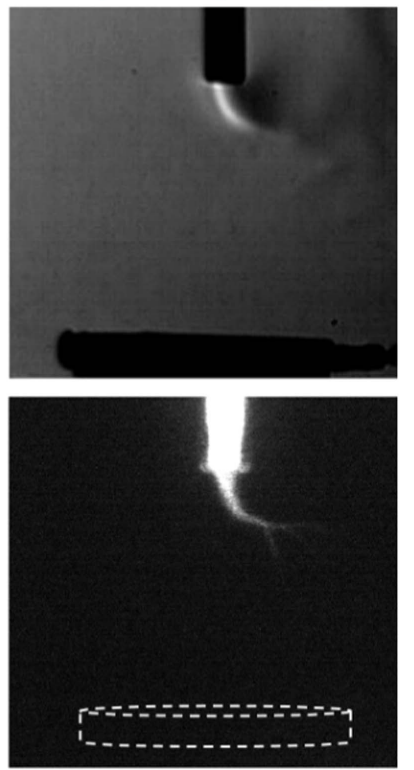

Figure 2. Helium flow with plasma off (a). Helium flow with plasma on for negative and positive polarities with a grounded metallic target located $2 \mathrm{~cm}$ (b) and $4 \mathrm{~cm}$ (c) downstream of the capillary outlet. Plasma plumes are imaged in corresponding configurations (integrated $10 \mu \mathrm{s})$. The applied voltage is $10 \mathrm{kV}$ and the pulse repetiton rate is $2 \mathrm{kHz}$.

expands at considerably longer distance than the negative plasma plume.

Thus, the plasma induces a force counterbalancing the buoyancy effects, which results in a downstream increase of the helium flow expansion. This force is drastically dependent on the polarity. Using negative polarity the buoyancy force is counterbalanced very efficiently up to several $\mathrm{cm}$, far beyond the plasma plume propagation distance. It can be pointed out that in the configuration of figure 2(c) for negative polarity, when the grounded target is removed (not shown), the maximal downstream expansion of the helium flow is reduced to $1.5 \mathrm{~cm}$. The influence of both the polarity of the applied voltage and the influence of a distant grounded target strongly support the electric nature of the force induced by the plasma.

Figure 3 shows the helium flow and the associated plasma plume emissions in the configuration of figure 2(b) ( $2 \mathrm{~cm}$ target gap) but for a $14 \mathrm{kV}$ applied voltage.

For negative polarity, the increase of the applied voltage results in the generation of a remarkably cylindrical helium channel compared to figure 2(b), which diameter is close to that of the capillary inner diameter. Reaching the target, the helium flow then horizontally spreads over the whole target surface. In this case, the negative plasma plume propagates only $5 \mathrm{~mm}$ downstream of the capillary outlet and still does not connect to the target.

For positive polarity, the helium channel remains perturbed with a winding shape and the helium only partially spreads over the target surface. The plasma plume connects to the target in a branched way. Those images of the helium flow are representative of the steady state achieved after plasma activation, especially for the negative polarity. A very stable
Plasma on negative polarity
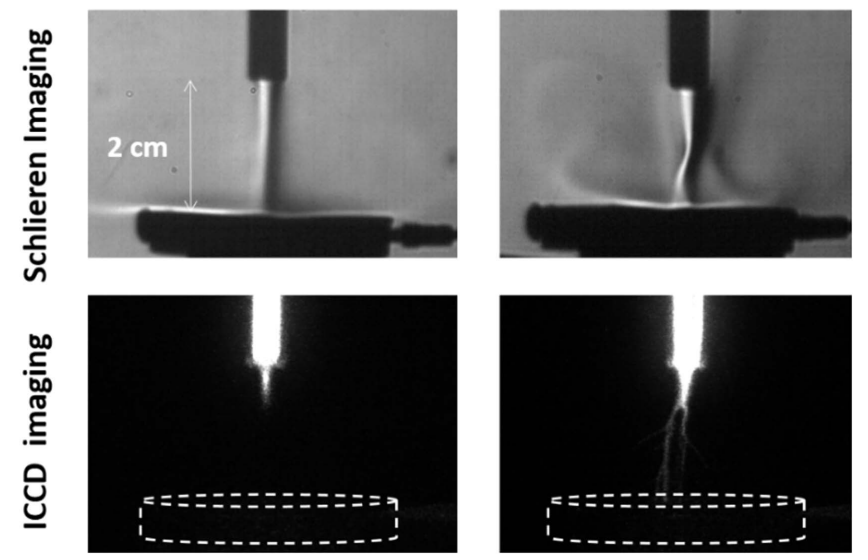

Figure 3. Helium flow modifcation with plasma on with a grounded metallic target located $2 \mathrm{~cm}$ downstream of the capillary outlet, for negative and positive polarities. Plasma plumes are imaged in corresponding configurations (integrated $10 \mu \mathrm{s}$ ). The applied voltage is $14 \mathrm{kV}$ and the pulse repetition rate is $2 \mathrm{kHz}$.

cylindrical helium channel is generated in this case, as long as the plasma is turned on. The plasma plume remains also very stable. For positive polarity however, the observed branching of the plume is more or less erratic with a perturbed helium channel.

These observations evidenced a fundamental distinction between the case of negative and positive polarities, both for the gas flow modifications and the plasma plume propagations. To explain the drastic difference between the negative 


\section{Negative polarity Positive polarity}

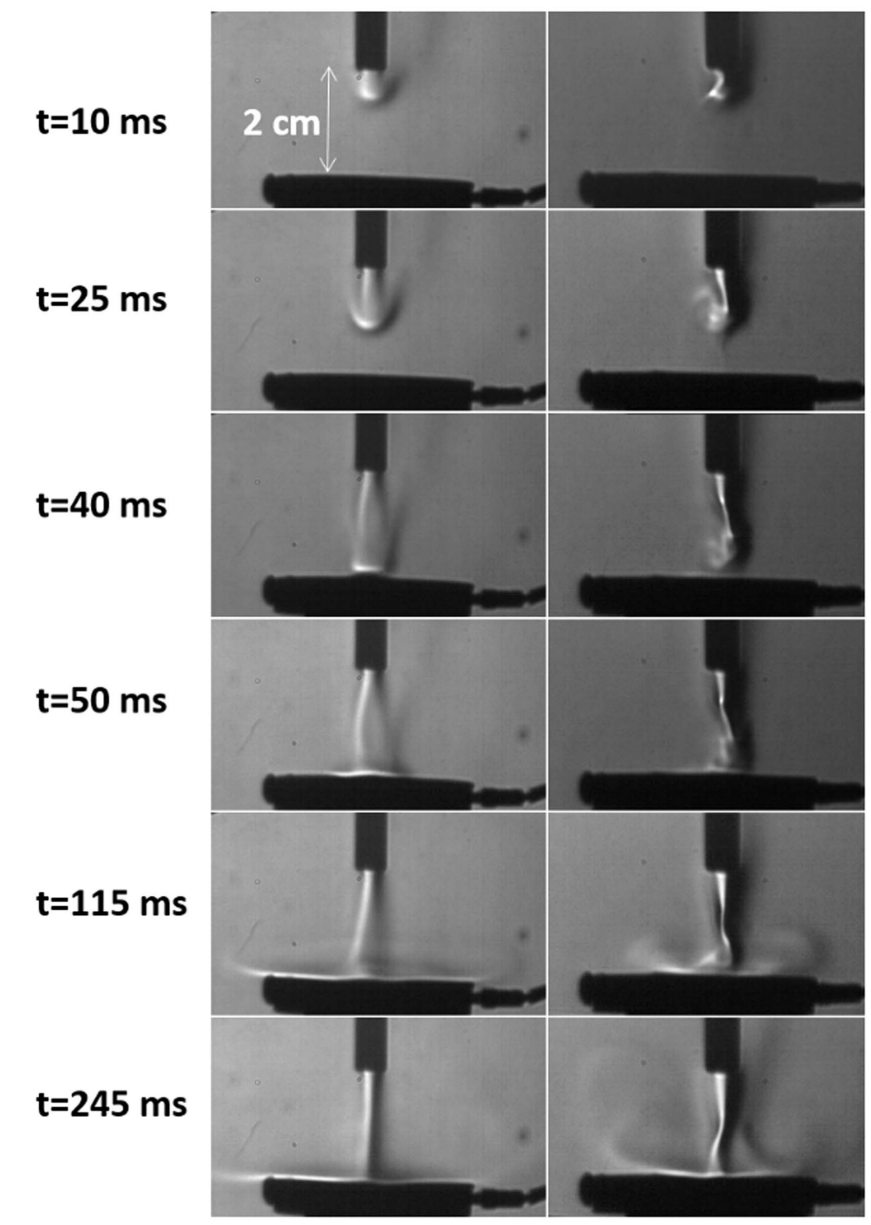

Figure 4. Helium channeling dynamics as a function of time after plasma has been turned on $(t=0)$ with a grounded metallic target located $2 \mathrm{~cm}$ downstream of the capillary outlet, for negative and positive polarities. The applied voltage is $14 \mathrm{kV}$ and the pulse repetition rate is $2 \mathrm{kHz}$.

and positive plasma plume length, the solely role of the helium mole fraction [10] cannot be involved in our experimental conditions. Precisely in our experimental conditions, a very short negative plasma plume propagation is associated with a large and well-structured helium channel in front of it. Whereas a much longer positive plasma plume is associated with the perturbed helium channel, where the mixing with ambient air is expected to be higher. Such variations of the air penetration in helium channel between the two polarities are also susceptible to influence the reactive species production in the plasma plume. This could also influence their quantitative measurements with absorption spectroscopy techniques, where the air mole fraction value is of importance for calibration procedure.

\subsection{Helium channeling dynamics}

As clearly shown in figure 3 , the use of a negative or positive polarity results in a drastic difference in the helium channel generation. Figure 4 shows the time resolved channeling dynamics, for the same conditions as in figure 3 , visualized right after the plasma is turned on $(t=0)$. The extremity of helium flow, at the interface with air, will be referred to as the 'helium front' of the helium channel.

For negative polarity, the helium front progressively expands downstream and reaches the middle of the gap at $t=25 \mathrm{~ms}$. Series of pictures (not shown) taken every ms show that the helium front impacts the target surface at $t=40 \mathrm{~ms}$. Then, the helium flow progressively spreads over the target surface (from 40 to $115 \mathrm{~ms}$ ). As long as the plasma is turned on, the channel remains very stable, as shown for $t=245 \mathrm{~ms}$. The propagation dynamics and the helium spreading over the target surface are gradual and fully reproducible each time the plasma is turned on with the same parameters. For positive polarity, the propagation of the helium front and the channeling are more erratic. Disturbed helium front is observed right after the plasma is turned on. Because of this erratic behavior, it is difficult to precisely measure when the helium reached the target, but this also occurs around $40 \mathrm{~ms}$.

The progressive regular expansion achieved for negative polarity allows to easily estimate the expansion velocity of the helium front. It has been found to be dependent on the applied voltage amplitude. For $14 \mathrm{kV}$ applied voltage, the expansion velocity is around $0.4 \mathrm{~mm} \mathrm{~ms}^{-1}(16 \mathrm{~mm}$ in $40 \mathrm{~ms})$. With the same target gap for a $10 \mathrm{kV}$ negative voltage (figure 2(b)) the expansion velocity is slower $(50 \mathrm{~ms}$ to reach the target, so around $\left.0.3 \mathrm{~mm} \mathrm{~ms}^{-1}\right)$. For a higher applied voltage $(18 \mathrm{kV}$, not shown), we found a higher expansion velocity (close to $0.5 \mathrm{~mm} \mathrm{~ms}^{-1}$ ). The expansion velocity has also been found to be sensitive to the target electrical characteristic. For a fixed $14 \mathrm{kV}$ applied voltage, the helium front reaches the grounded target surface at $40 \mathrm{~ms}$, while the helium front is still located $2 \mathrm{~mm}$ above the surface when the target is at floating potential. In that latter case, considering the fact that the energy deposition in the plasma reactor is exactly the same in both cases, this confirms that thermal effects are probably not at the origin of the observed results.

The helium front expansion velocity dependence on the applied voltage amplitude and on the target electrical characteristics suggests an ionic wind type action mechanism. The ions are accelerated by the electric field and then they transfer their kinetic energy to the surrounding neutrals by collision. The kinetic energy of ions is directly dependent on the electric field amplitude and on topology. The negative plasma plume tip, imaged in figure 3, supplies the laplacian electric field in the gap between the plasma plume tip and the grounded target. As experimentally shown in previous works, Darny et al [5] and Robert et al [23], and modeled by Bourdon et al [30], the partial transmission of the potential applied on the inner high voltage electrode through the conductive ionized channel leads to a radial electric field generation (laplacian electric field) along it. In front of the plasma plume tip, the laplacian electric field lines are connected to the grounded target, like in corona discharge. In these conditions, the amplitude of the applied voltage on the inner electrode and the electrical characteristics of the target directly change the electric field amplitude and topology in the volume comprised between the 


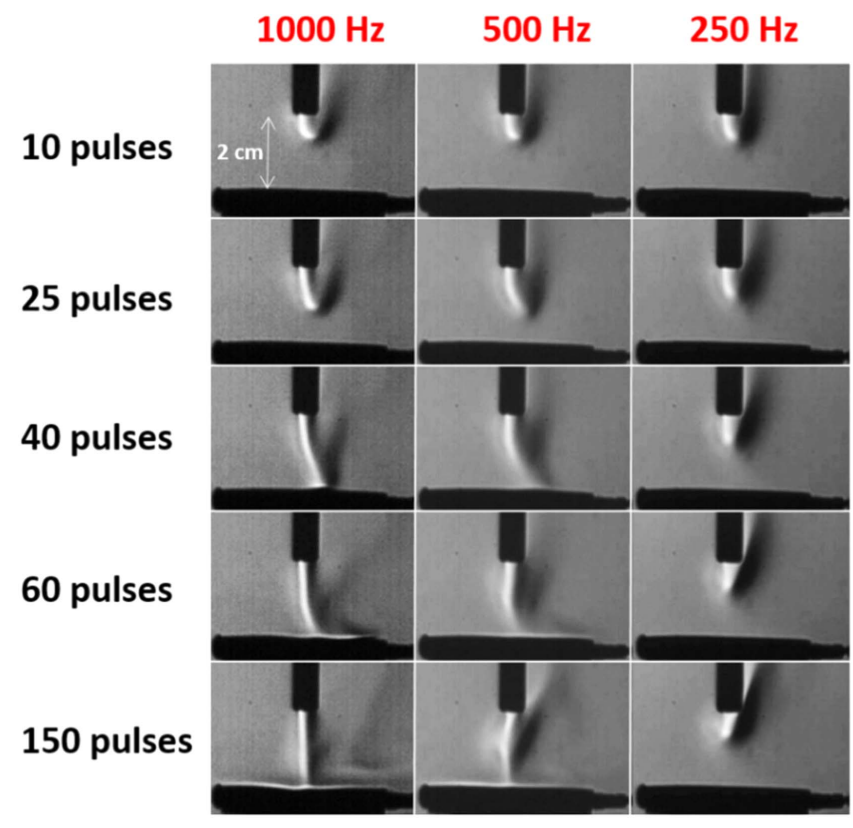

Figure 5. Helium channeling dynamics as a function of the number of voltage pulses after plasma has been turned on, for three different pulse repetition rates. The target gap is $2 \mathrm{~cm}$ and the applied voltage is $14 \mathrm{kV}$ for negative polarity.

plasma plume and the target. This leads to change the kinetic energy of ions which are accelerated toward the target.

Furthermore, since the jet is oriented in the downward direction, like in the case of most of the biomedical applications, the helium front propagation principally results from the balance between two forces: the momentum of the ionic wind (downward direction) and the buoyancy (upward direction). When the helium front propagates as shown in figure 4 , the buoyancy force is continuously active. However, the ions can only be accelerated when electric field is applied, i.e. during the application of the voltage pulse. Considering that the voltage pulse is applied about $10 \mu$ s (see figure 1(b)), ions drift in the electric field is active during about $1 \%$ of the time between successive pulses at $1 \mathrm{kHz}$ repetition rate. Thus most of the time, only sufficiently long lifetime ions or neutrals being accelerated during this $1 \%$ active phase still play a role in the helium channeling mechanism before next voltage pulse application. This suggests that there might be a lower limit of the pulse repetition rate to maintain the observed helium flow channeling. Figure 5 presents the results obtained on the channeling dynamics as a function of the number of pulses for three decreasing values of the pulse repetition rates $(1000,500$ and $250 \mathrm{~Hz})$. All data are obtained for a $14 \mathrm{kV}$ applied voltage for negative polarity, as for the case displayed in figures 3 and 4.

For $1000 \mathrm{~Hz}$, the helium front propagates and reaches the target after 40 pulses. This corresponds to the same delay (40 ms) between plasma ignition and target impact than for the case with a $2 \mathrm{kHz}$ pulse repetition rate displayed in figure 4 , but with a half number of pulses. A stable cylindrical channel (like the one depicted in figure 4) is established after the cumulative effect of 150 pulses. It remains stable as long as the plasma is turned on.
For $500 \mathrm{~Hz}$, the helium also reaches the target with 40 pulses, but this corresponds to a duration twice longer than for the case with a pulse frequency of $1000 \mathrm{~Hz}(80 \mathrm{~ms}$ instead of $40 \mathrm{~ms}$ ). The channeling is also less effective since the channel structure remains perturbed with 150 pulses.

Finally for $250 \mathrm{~Hz}$, the channeling never occurs whatever the number of applied pulses. This indicates that if the time delay between two pulses is too long $(4 \mathrm{~ms}$ at $250 \mathrm{~Hz}$ ), the added momentum by one pulse has been damped before the next pulse is applied, preventing from a cumulative momentum produced by the ionic wind. The kinetic energy transferred from the ions to the neutrals is progressively damped and the buoyancy force becomes dominant again.

Consequently, it appears that with a delay of $4 \mathrm{~ms}$ between each pulse, the effect of added momentum is almost completely lost from one pulse to another. However, if the time between two consecutive pulses is short enough (i.e. $\sim 2 \mathrm{~ms}$ ), the next pulse is applied before the extra momentum given to the neutrals from the previous pulse has been damped. This means that to efficiently shift downstream the effects of buoyancy force between two pulses, the second pulse must be applied before the neutrals have completely lost the added momentum due to the previous pulse. Thus, the required pulse repetition rate threshold to build a helium channel in our experimental conditions lies between 250 and $500 \mathrm{~Hz}$. The threshold to build a stabilized helium channel lies between 500 and $1000 \mathrm{~Hz}$.

\subsection{Role of positive and negative ions}

To explain the dramatic change between positive and negative polarities in the helium channeling, some analogies can be made with previously reported phenomena linked to plasma actuators. In the study of Enloe et al [31] on DBD plasma actuators, it was shown that the thrust (i.e. the momentum associated to the ionic wind) was not the same for positive and negative voltage polarities. They compared negative and positive saw tooth voltages and they observed a more efficient momentum transfer from ions to neutrals in the case of a negative saw tooth voltage than for a positive one. They excluded any thermal effects resulting from plasma heating to explain the observed difference between the two polarities. In 2008, Enloe et al [32] have shown that $97 \%$ of momentum transfers occurred in the negative half cycle for DBD actuator powered by a sinusoidal voltage. They used the oscillatory motion of a vertical pendulum coupled with a Michelson interferometer to access to the time resolved force developed by the plasma. These results were also confirmed by Kim et al [33] with phase locked particle image velocimetry.

In [32], Enloe et al have shown that momentum transfer during the positive half cycle compared to the negative one was not only different in magnitude but also in direction. They correlated this observation with the dramatic change in the discharge structure, depending on negative or positive half cycle. An homogeneous discharge was obtained during the negative half cycle while a very filamentary one was obtained during the positive half cycle. Controlling the ratio between oxygen and nitrogen, they also observed a substantial increase 
of the force produced by the plasma in the presence of oxygen. In [33], Kim et al also observed a correlation between the presence of oxygen and the actuators efficiency. They emphasized on the role of negative ions formation, especially $\mathrm{O}_{2}{ }^{-}$. It was shown in the phenomenological model of Soloviev [34] (surface DBD) that the negative half cycle promoted the formation of long lifetime $\mathrm{O}_{2}{ }^{-}$and $\mathrm{O}_{3}{ }^{-}$ions. The volumetric accumulation of these long lifetime negative ions was correlated with the higher performance of the actuator in the negative half cycle. The higher thrust with higher applied voltage was also attributed to a higher accumulation of negative ions.

It was found that negative ions also plays a key role in corona actuators discharge in air [35-37]. Very long lifetime 'terminal ions' were measured with mass spectrometry. The ion with the longer lifetime in air was $\mathrm{NO}_{3}{ }^{-}$with a lifetime around $10 \mathrm{~s}$. This ion can form heavy hydrated cluster $\mathrm{NO}_{3}{ }^{-}\left(\mathrm{H}_{2} \mathrm{O}\right)_{n}$ in humid air. The $\mathrm{NO}_{2}^{-}$ion also has a long lifetime (longer than $1 \mathrm{~s}$ ) and $\mathrm{OH}^{-}$has a lifetime of the millisecond order. They can also form heavy clusters. It was underlined in [31] that the chemistry of negative ions is very complex, due to the long lifetime and great variety of ions produced, compared to the positive ions chemistry, mainly with a shorter lifetime and a reduced variety.

In a cold atmospheric pressure helium plasma jet, Oh et al [38] measured by mass spectrometry a great variety of negatives ions (34 species), compared to positive ions (11 species). Most of the observed negative ions consisted in water clusters. The positive ions were mainly lighter, with shorter lifetime, compared to the negative ones. Nevertheless, they also measured few positive ion clusters. In [39], Oh et al have confirmed that the dominant negative ions were $\mathrm{O}^{-}$, $\mathrm{O}_{2}{ }^{-}, \mathrm{O}_{3}{ }^{-}$and $\mathrm{NO}_{3}{ }^{-}$for a helium plasma jet with a $2.4 \mathrm{~mm}$ inner diameter capillary and for both pulsed DC and sinusoidal $\mathrm{kHz}$ excitation. The dominant positive ions were $\mathrm{He}^{+}$, $\mathrm{N}^{+}, \mathrm{O}^{+}, \mathrm{H}_{2} \mathrm{O}^{+}, \mathrm{N}_{2}{ }^{+}$and $\mathrm{O}_{2}{ }^{+}$.

To explain the generation of the cylindrical helium channel depicted in figure 4 , we focus on the case with the negative polarity where there is an active role of the largest and longer lifetime negative ions. As reported by Douat et al [40], the negative plasma plume exhibits an annular structure. Consequently, in the plasma plume vicinity close to the capillary outlet, the negative ions are likely to be generated mainly by transfers at the boundary of the cylindrical helium channel, where the mixing with air is also the highest. This should result in a cylinder-like arrangement of negative ions. In front of the negative plasma tip, the negative ions are pushed in the direction of the target surface. These negative ions drift together with the helium flow, at the boundary of the helium channel. Along the plasma plume, because of the laplacian electric field in the radial direction, the negative ions are likely to be slightly pushed in the radial direction at first. These ions do not participate to the downstream expansion of the helium flow (the drift direction on these ions is almost perpendicular to the flow direction), but this may reduce the air penetration in the helium channel. For negative polarity, the helium channel results from the negative ions pushing in the flow downstream direction, with a very effective momentum transfer to neutrals. The lighter positive ions move in the upward direction, with a less effective momentum transfer compared to the negative ones.

The helium channeling mechanism is summarized with a schematic view in figure 6 , based on the experimental conditions of the configuration displayed in figure 4 for negative polarity. For the clarity of the sketch, only the ionic wind induced streamwise momentum is represented. The helium flow upstream expansion at the edge of the helium front is not represented.

- $t=0$ (plasma off): the helium flow expands $4 \mathrm{~mm}$ downstream of the capillary outlet for $0.51 \mathrm{~min}^{-1}$ flow rate ( $4 \mathrm{~mm}$ inner diameter capillary). This results from the equilibrium between two opposite forces: the natural inertia in the downward direction (bulk velocity about $0.7 \mathrm{~mm} \mathrm{~ms}^{-1}$ within the capillary) and the buoyancy (upward direction). Downstream of the capillary outlet, the natural inertia progressively diminishes and finally vanishes at $4 \mathrm{~mm}$. The interface between the helium and the air is referred to as the 'helium front'.

- $t=10$ ms after plasma on: repetition of added momentum due to the ionic wind at each voltage pulse. The accelerated negative ions collide with initially 'static' neutrals. The time delay between two pulses must be short enough to efficiently counterbalance the effects of buoyancy. With the succession of ionic wind induced momentum, the helium front propagation starts $\left(0.2 \mathrm{~mm} \mathrm{~ms}^{-1}\right)$.

- $t=25 \mathrm{~ms}$ after plasma on: in the helium channel (behind the helium front) neutrals have always a natural inertia. The added momentum due to ionic wind is combined with the natural inertia (entrainment effect). The combination of both momenta is more effective to counterbalance the buoyancy force and the helium front propagation accelerates $\left(0.4 \mathrm{~mm} \mathrm{~ms}^{-1}\right)$. The entrainment effect is sustained when the pulse repetition rate is high enough, in order not to lose the benefits of natural inertia between two pulses.

- $t=40 \mathrm{~ms}$ after plasma on: the helium front impacts the target surface. A cylindrical helium channel is established between the capillary outlet and the target surface.

- $t=245 \mathrm{~ms}$ after plasma on: the natural inertia (horizontal direction) convects the ions along the target surface and the ionic wind prevents upward expansion due to the vertical force applied. A helium layer is trapped over the target surface. This configuration is very stable as long as the plasma is turned on and supports the role of long lifetime negative ions.

Comparing the gas flow modification for negative and positive polarities, it is then assumed that the dramatic change of the gas flow modifications between the negative and positive polarities is primarily due to the change of the drift direction of the negative ions. In the positive case, the role of positive and negative ions is inverted, regarding the helium flow expansion. The positive ions (mainly lighter with shorter lifetime compared to the negative ones) are pushed in the downstream direction. In this case, the negative ions are 

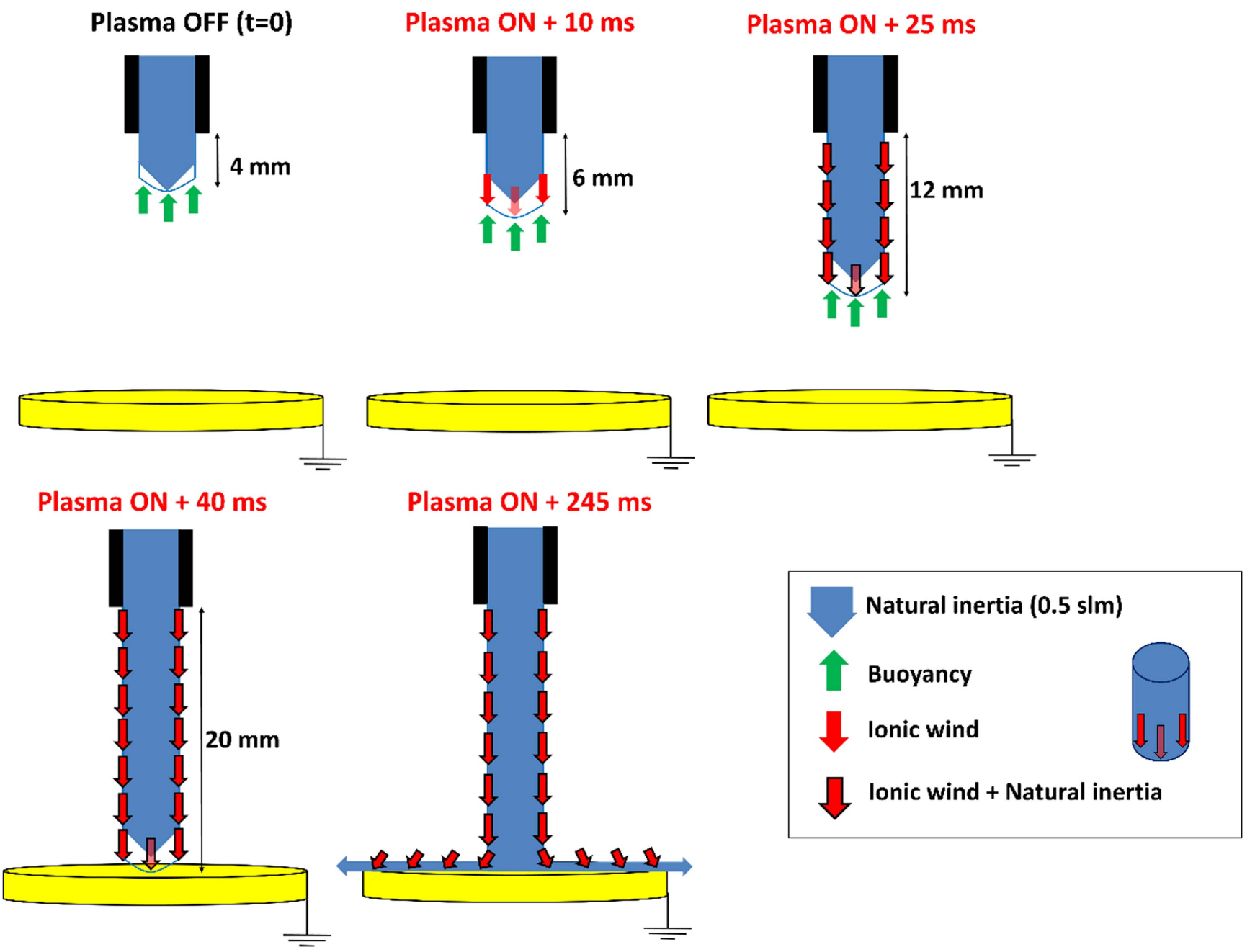

Figure 6. Shematic view of the helium channeling mechanism in the conditions of figure 4 (negative polarity). The ionic wind arrows are located on the boundary of the cylindrical helium channel (perspective view is given in the insert).

pulled away and have a destructive effect on the helium channel. The positive ions are mainly confined in the vicinity of the plasma because of their shorter lifetimes. This may explain the very disturbed shape of the helium front for positive polarity and the direct correlation between the plasma plume and the helium channel patterns. Also in this case, the helium flow has never been observed to spread over the whole target surface.

For negative polarity, the spreading of the helium flow over the whole grounded target surface is an indication of the presence of the long lifetime negative ions. In exactly the same experimental conditions, figure 7 shows a comparison between the spreading of helium over grounded and floating target surfaces.

For the grounded target configuration, the helium has already spread over the whole surface $125 \mathrm{~ms}$ after the plasma activation. This flow configuration remains stable as long as the plasma is turned on, as shown at 250 and $335 \mathrm{~ms}$. Conversely with the target at floating potential, the helium doesn't spread over the whole target surface at $125 \mathrm{~ms}$. Moreover, the helium flow is progressively pushed away from the target in the upward direction between 250 and $335 \mathrm{~ms}$ (6 mm upward

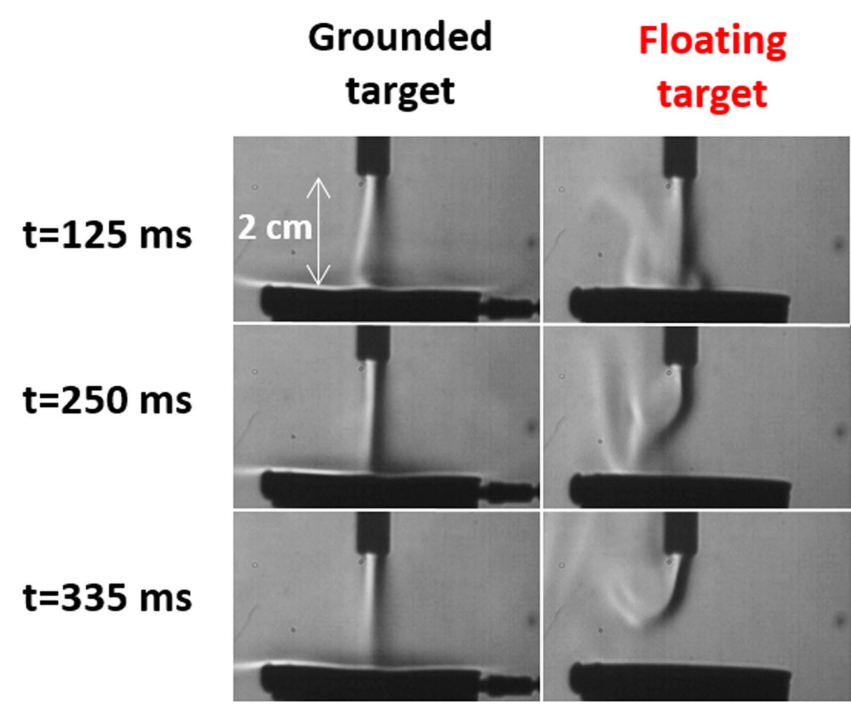

Figure 7. Spreading of the helium flow over the grounded/floating metallic target surface after the plasma has been turned on at $t=0$. The applied voltage is $14 \mathrm{kV}$ for negative polarity and the pulse repetition rate is $2 \mathrm{kHz}$. 
$50^{\text {th }}$ negative pulse

a.

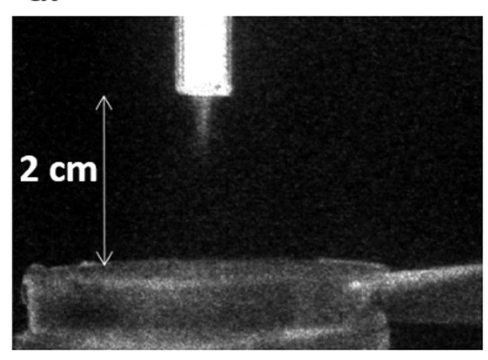

b.

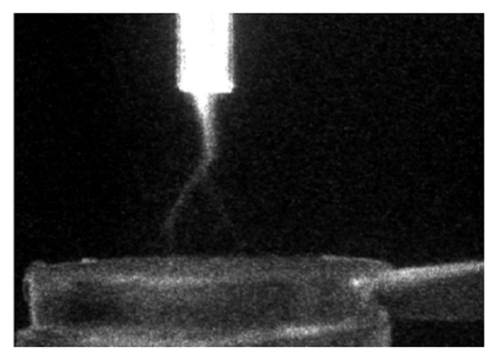

$1^{\text {rst }}$ positive pulse after c. 50 negative pulses

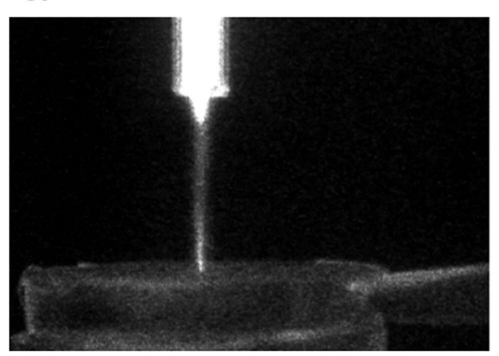

Figure 8. ICCD imaging ( $1 \mathrm{~ms}$ integration) of plasma plume for negative (a) and positive (b) polarity at the 50th pulse and at the first positive pulse after 50 negatives pulses (c). The applied voltage is $14 \mathrm{kV}$ and the pulse repetition rate is $1 \mathrm{kHz}$.

of the target surface at this time). This can be explained by the accumulation of long lifetime negative ions on the floating target surface. This leads to a negative space charge electric field generation which electrostatically repels the negative ions flowing in the helium channel.

The gas flow interaction with the target is important to consider for reactive species production, transport and deposition on samples, as shown by Tian et al [41]. It must be also emphasized that great care must be taken in translating the results obtained in case of free jet configuration to an application. It must be stressed that only diagnostics performed in situ in real application conditions can give a reliable view of what is really happening or produced. This is especially true for in vitro and in vivo applications where the nature of the target can greatly impact the rare gas/air mixing in its environment.

\subsection{Use of helium channeling features for plasma enhanced propagation}

Drastic modifications have been observed when using negative or positive applied voltage, both for the helium flow modification and the plasma plume propagation. In the experimental conditions of figures 3 and 4, a stable cylindrical helium channel is generated with the repetition of negative voltage pulses but the negative plasma plume only propagates $5 \mathrm{~mm}$ below the capillary outlet. For positive polarity however, the positive plasma plume is connected to the target surface but with a more or less erratic branching and a perturbed helium channel, as long as the plasma is turned on.

Figures 8(a) and (b) show these patterns of negative and positive plasma plumes, with the grounded target located $2 \mathrm{~cm}$ downstream of the capillary outlet, for $14 \mathrm{kV}$ negative applied voltage at $1 \mathrm{kHz}$ pulse repetition rate. The ICCD camera acquisition is delayed at the 50th pulse after the plasma activation. The light collected ( $1 \mathrm{~ms}$ integrated) corresponds to the plasma plume emission at $50 \mathrm{~ms}$. At this time, the helium channel is established between the capillary outlet and the target. The very short negative plasma plume exhibits a conical shape, while the positive plasma plume connects to the target with branching. The branching in the positive plasma plume cannot be controlled and is changing at each pulse.
Very interestingly, it is illustrated in figure 8(c) that it is possible to take advantage of both negative and positive polarity pulse features with an appropriate combination between them. The plasma plume is shown at the first positive pulse after 50 negative ones. The latter are used to build a cylindrical helium channel. After the 50th negative pulse, the polarity is switched to positive allowing a first positive pulse $1 \mathrm{~ms}$ later. In such operating conditions, the plasma plume is focused on the capillary axis and impact the target in a localized spot, conversely to what is shown in figure 8(b). Secondly, the branching of the plasma plume, usually always observed using positive polarity in this geometric conditions, is here inhibited. This leads to a very stable and reproducible plasma plume development, each time the first positive pulse is launched after the repetition of the negative pulses.

The generation of a focused positive plasma plume on the capillary axis without branching may result of the peculiar cylindrical arrangement of negative ions at the boundary of the cylindrical helium channel, as depicted in figure 6. This evidenced the crucial role of the charged flow background for the plasma plume development. To the best of our knowledge, this is the first time in plasma jet experiments that such fluid pattern is achieved for the optimization of the plasma plume propagation. This can be used to treat specific area in 'one' shot experiment, for example for micropatterning.

\section{Conclusions}

In this paper we have studied the helium flow modification induced by the plasma for a low helium flow rate condition with the jet oriented in the downward direction, as used in most of biomedical treatments. While the helium flow without plasma only expands few $\mathrm{mm}$ downstream of the capillary outlet, the plasma activation results in an EHD force generation which leads to greatly enhance the helium flow downstream expansion, allowing to reach a target few $\mathrm{cm}$ below. The EHD force counterbalances the buoyancy force, with a drastic dependence of the applied voltage polarity (very effective for negative compared to positive one). This is explained by the drift direction of long lifetime negative ions together with the helium flow toward the target, when negative polarity pulses are used. The negative plasma plume tip 
supplies the laplacian electric field in the gap between the plasma plume tip and the grounded target. If the pulse repetition rate is high enough (between 500 and $1000 \mathrm{~Hz}$ in our conditions), the extra streamwise momentum resulting from successive pulses due to ionic wind combines with the natural inertia of the flow in the laminar regime. This leads to the generation of a stable cylindrical helium channel with a spreading of the flow over the whole grounded target surface, as long as the plasma is turned on. Such stable flow condition cannot be achieved using positive polarity pulses, where the helium channel remains in this case perturbed during plasma activation. The change of stable flow condition between the two polarities results in different mixing with ambient air, which is important to take into account for reactive species production, transport and also quantitative measurements. It has been shown that the cylindrical channel build up, resulting from the application of a series of negative pulses, offers unique opportunity to launch a ionization wave allowing a stable and straight connection of the plasma plume, powered by a positive voltage pulse, to a distant target.

\section{Acknowledgments}

This work is supported by ANR BLANC 093003 PAMPA, TD is supported by MENSR.

\section{References}

[1] Winter J, Brandenburg R and Weltmann K-D 2015 Atmospheric pressure plasma jets: an overview of devices and new directions Plasma Sources Sci. Technol. 2464001

[2] Lu X, Naidis G V, Laroussi M, Reuter S, Graves D B and Ostrikov K 2016 Reactive species in non-equilibrium atmospheric-pressure plasmas: generation, transport, and biological effects Phys. Rep. 630 1-84

[3] Murakami T, Niemi K, Gans T, O'Connell D and Graham W G 2013 Chemical kinetics and reactive species in atmospheric pressure helium-oxygen plasmas with humid-air impurities Plasma Sources Sci. Technol. 2215003

[4] Takeda K, Kumakura T, Ishikawa K, Tanaka H, Sekine M and Hori M 2017 Behavior of absolute densities of atomic oxygen in the gas phase near an object surface in an ACexcited atmospheric pressure He plasma jet Appl. Phys. Express 1036201

[5] Darny T, Pouvesle J-M, Puech V, Douat C, Dozias S and Robert E 2017 Analysis of conductive target influence in plasma jet experiments through helium metastable and electric field measurements Plasma Sources Sci. Technol. 26 45008

[6] Oh J, Olabanji O T, Hale C, Mariani R, Kontis K and Bradley J W 2011 Imaging gas and plasma interactions in the surface-chemical modification of polymers using microplasma jets J. Phys. D: Appl. Phys. 44155206

[7] Jiang N, Yang J, He F and Cao Z 2011 Interplay of discharge and gas flow in atmospheric pressure plasma jets J. Appl. Phys. 109093305

[8] Ghasemi M, Olszewski P, Bradley J W and Walsh J L 2013 Interaction of multiple plasma plumes in an atmospheric pressure plasma jet array J. Phys. D: Appl. Phys. 4652001

[9] Shao X, Chang Z, Mu H, Liao W-L and Zhang G-J 2013 Experimental and numerical investigation on the interaction between Ar flow channel and Ar plasma jet at atmospheric pressure IEEE Trans. Plasma Sci. 41 899-906

[10] Karakas E, Koklu M and Laroussi M 2010 Correlation between helium mole fraction and plasma bullet propagation in low temperature plasma jets J. Phys. D: Appl. Phys. 43 155202

[11] Bradley J W, Oh J S, Olabanji O T, Hale C, Mariani R and Kontis K 2011 Schlieren photography of the outflow from a plasma jet IEEE Trans. Plasma Sci. 39 2312-3

[12] Foletto M, Puech V, Fontane J, Joly L and Pitchford L C 2014 Evidence of the influence of plasma jets on a helium flow into open air IEEE Trans. Plasma Sci. 42 2436-7

[13] Xiong R, Xiong Q, Nikiforov A Y, Vanraes P and Leys C 2012 Influence of helium mole fraction distribution on the properties of cold atmospheric pressure helium plasma jets J. Appl. Phys. 112 1-9

[14] Yamamoto A, Kawano Y, Nakai M, Nakagawa T, Sakugawa T, Hosseini H and Akiyama H 2015 Investigation of gas flow dependence of plasma jet produced by pulsed power IEEE Trans. Plasma Sci. $\mathbf{4 3}$ 3451-5

[15] Darny T, Robert E, Ries D, Dozias S and Pouvesle J M 2014 Unexpected plasma plume shapes produced by a microsecond plasma gun discharge IEEE Trans. Plasma Sci. 42 2504-5

[16] Bin Xian Y, Hasnain Qaisrani M, Yue Y F and Lu X P 2016 Discharge effects on gas flow dynamics in a plasma jet Phys. Plasmas 23103509

[17] Papadopoulos P K, Vafeas P, Svarnas P, Gazeli K, Hatzikonstantinou P M, Gkelios A and Clément F 2014 Interpretation of the gas flow field modification induced by guided streamer ('plasma bullet') propagation $J$. Phys. D: Appl. Phys. 47425203

[18] Boselli M, Colombo V, Ghedini E, Gherardi M, Laurita R, Liguori A, Sanibondi P and Stancampiano A 2014 Schlieren high-speed imaging of a nanosecond pulsed atmospheric pressure non-equilibrium plasma jet Plasma Chem. Plasma Process. 34 853-69

[19] Zhang S, Sobota A, van Veldhuizen E M and Bruggeman P J 2015 Gas flow characteristics of a time modulated APPJ: the effect of gas heating on flow dynamics J. Phys. D: Appl. Phys. 4815203

[20] Hasan M I and Bradley J W 2016 Reassessment of the body forces in a $\mathrm{He}$ atmospheric-pressure plasma jet: a modelling study J. Phys. D: Appl. Phys. 4955203

[21] Zheng Y, Wang L, Ning W and Jia S 2016 Schlieren imaging investigation of the hydrodynamics of atmospheric helium plasma jets J. Appl. Phys. 119123301

[22] Robert E, Sarron V, Darny T, Riès D, Dozias S, Fontane J, Joly L and Pouvesle J-M 2014 Rare gas flow structuration in plasma jet experiments Plasma Sources Sci. Technol. 23 12003

[23] Robert E, Darny T, Dozias S, Iseni S and Pouvesle J M 2015 New insights on the propagation of pulsed atmospheric plasma streams: from single jet to multi jet arrays Phys. Plasmas 22122007

[24] Robert E, Sarron V, Riès D, Dozias S, Vandamme M and Pouvesle J-M 2012 Characterization of pulsed atmosphericpressure plasma streams (PAPS) generated by a plasma gun Plasma Sources Sci. Technol. 2134017

[25] Vandamme $\mathrm{M}$ et al 2012 ROS implication in a new antitumor strategy based on non-thermal plasma Int. J. Cancer 130 2185-94

[26] Brullé L, Vandamme M, Ries D, Martel E, Robert E, Lerondel S, Trichet V, Richard S, Pouvesle J M and Le Pape A 2012 Effects of a non thermal plasma treatment alone or in combination with gemcitabine in a MIA PaCa2luc orthotopic pancreatic carcinoma model PLoS One 7 1-10

[27] Collet G, Robert E, Lenoir A, Vandamme M, Darny T, Dozias S, Kieda C and Pouvesle J M 2014 Plasma jet- 
induced tissue oxygenation: potentialities for new therapeutic strategies Plasma Sources Sci. Technol. 23 12005

[28] Settles G S 2001 Schlieren and Shadowgraph Techniques: Visualizing Phenomena in Transparent Media (Berlin: Springer) (https://doi.org/10.1007/978-3-642-56640-0)

[29] Sutera S P and Skalak R 1993 The history of poiseuille law Annu. Rev. Fluid Mech. 25 1-19

[30] Bourdon A, Darny T, Pechereau F, Pouvesle J-M, Viegas P, Iséni $S$ and Robert E 2016 Numerical and experimental study of the dynamics of a $\mu$ s helium plasma gun discharge with various amounts of $\mathrm{N}_{2}$ admixture Plasma Sources Sci. Technol. 2535002

[31] Enloe C L, McLaughlin T E, Van Dyken R D, Kachner K D, Jumper E J and Corke T C 2004 Mechanisms and responses of a single dielectric barrier plasma actuator: plasma morphology AIAA J. 42 589-94

[32] Enloe C L, McHarg M G and McLaughlin T E 2008 Timecorrelated force production measurements of the dielectric barrier discharge plasma aerodynamic actuator J. Appl. Phys. 10373302

[33] Kim W, Do H, Mungal M G and Cappelli M A 2007 On the role of oxygen in dielectric barrier discharge actuation of aerodynamic flows Appl. Phys. Lett. 91 2007-9

[34] Soloviev V R 2011 Analytical estimation of the thrust generated by a surface dielectric barrier discharge $J$. Phys. D: Appl. Phys. 4525205
[35] Nagato K, Matsui Y, Miyata T and Yamauchi T 2006 An analysis of the evolution of negative ions produced by a corona ionizer in air Int. J. Mass Spectrom. 248 142-7

[36] Sekimoto K and Takayama M 2007 Influence of needle voltage on the formation of negative core ions using atmospheric pressure corona discharge in air Int. J. Mass Spectrom. 261 $38-44$

[37] Sekimoto K and Takayama M 2010 Negative ion formation and evolution in atmospheric pressure corona discharges between point-to-plane electrodes with arbitrary needle angle Eur. Phys. J. D 60 589-99

[38] Oh J-S, Aranda-Gonzalvo Y and Bradley J W 2011 Timeresolved mass spectroscopic studies of an atmospheric-pressure helium microplasma jet J. Phys. D: Appl. Phys. 44 365202

[39] McKay K, Oh J-S, Walsh J L and Bradley J W 2013 Mass spectrometric diagnosis of an atmospheric pressure helium microplasma jet J. Phys. D: Appl. Phys. 46464018

[40] Douat C, Kacem I, Sadeghi N, Bauville G, Fleury M and Puech V 2016 Space-time resolved density of helium metastable atoms in a nanosecond pulsed plasma jet: influence of high voltage and pulse frequency $J$. Phys. $D$ : Appl. Phys. 49285204

[41] Tian W, Lietz A M and Kushner M J 2016 The consequences of air flow on the distribution of aqueous species during dielectric barrier discharge treatment of thin water layers Plasma Sources Sci. Technol. 2555020 